\title{
Interlaminar Tests for Marine Applications. Evaluation of the Influence of Peel Plies and Fabrication Delays
}

\author{
P. Davies ${ }^{1^{*}}$, C. Baley ${ }^{2}$, H. Loaec ${ }^{1}$ and Y. Grohens ${ }^{2}$ \\ ${ }^{1}$ Materials \& Structures group, IFREMER Centre de Brest, 29280 Plouzané, France \\ ${ }^{2}$ L2P, Université de Bretagne Sud, 56321 Lorient, France \\ *: Corresponding author : peter.davies@ifremer.fr
}

\begin{abstract}
This paper presents results from a study of the influence of surface preparation on the mechanical performance of overlaminated polyester composites. Panels of 16 woven glass plies have been prepared in two halves by hand lay-up. After the first 8 plies were laminated the surface was either protected by a peel ply or left in air. The overlamination of the second half of the composite thickness was completed after different periods and interlaminar shear, flexure and mode I fracture specimens were tested. The results enabled the influence of the delay and the surface condition to be related to mechanical performance. Surfaces protected with peel plies show very low Glc propagation energy release rates. Results are compared to those from continuous lamination of the 16 ply composite. Interlaminar fracture tests are shown to be much more sensitive to overlamination conditions than the traditional short beam shear test. Results are interpreted in terms of fracture surface features.
\end{abstract}

Keywords: interlaminar - overlamination - glass/polyester - peel ply - woven - mode 


\section{Introduction}

Most composite manufacturing processes involve the assembly of composite components, either in one or multiple steps. For example a complete racing yacht structure with integral stiffeners may be fabricated in one shot in an autoclave or a structure such as a pleasure boat hull may be produced in a mould and then stiffeners over-laminated in a second step [1,2]. In both cases there is a need to optimise the mechanical strength of the interfaces between components.

This paper describes a study of over-lamination. This is a procedure widely used in the marine industry (for both pleasure boats and military ships) and involves wet lay-up of glass fibres and resin onto a partly- or fully-cured substrate. There are many parameters which can influence the behaviour of the interface, but two which have been seen to be critical are:

- the delay period between completion of the substrate and over-lamination, and

- the preparation of the substrate surface.

It should be emphasised that the polyester resins most frequently used in the marine industry are not post-cured and will continue to cure naturally for days or weeks after fabrication. Thus the longer the delay before over-lamination the less likelihood of strong chemical bonds being formed with the new laminate. Styrene may also be lost from the surface resulting in local changes in stoichiometry. This situation may be worsened if additives, such as those present in some low styrene emission resins, can migrate to the surface [3]. There are different surface preparations available. The simplest is to apply a release fabric or "peel ply", typically a nylon or polyester fabric, which protects the surface and is removed just before over-lamination to reveal a new surface. These fabrics are generally fine weave cloths and are often recommended to enable secondary bonding to be applied without further surface preparation. However, there are dozens of peel ply grades available many of which include surface finishes to facilitate removal. These finishes may be silicone or fluorocarbon based and there may be a risk of surface contamination. Several previous studies have highlighted the risks associated with nylon peel plies in the adhesive bonding of aeronautical epoxy and bismaleimide composites [4-7]. Tests are therefore essential to check the compatibility of the peel ply with the composite system. Other surface preparations include abrasion, solvent cleaning, or even grinding to ensure that a clean, uncontaminated surface is offered to the overlaminate. In the present work the two simplest surface preparations have been examined, namely with or without a peel ply. Further work is examining more complicated surface treatments.

There are relatively few practical options for characterising interfaces such as these [8]. The most widely used method is the standard short beam shear (ILSS) test. This requires little material and can produce useful qualitative results if care is taken, but it may also produce failure modes other than interface failure and results cannot be used in design calculations. In order to obtain more valid shear strength data more complex and expensive specimens such as the Iosipescu beam are required. There are also through-thickness tensile tests available but again they require complicated specimens and are not very satisfactory. An alternative approach is to place an insert film at the interface of interest, and measure the energy needed to propagate a crack along it with fracture mechanics tests. Few studies have been reported for this kind of application of fracture tests and one of the aims of the present work was to determine whether such tests offered any advantages compared to the conventional test methods. 


\section{Materials}

The materials tested in the present study are all woven glass reinforced polyester composites. The reinforcement consists of 16 plies of $500 \mathrm{~g} / \mathrm{m}^{2}$ woven $\mathrm{E}$ glass (balanced $0 / 90^{\circ}$ ), about 8 $\mathrm{mm}$ total thickness, (see Table 1), in a pre-accelerated isophthalic unsaturated polyester (Cray Valley 703 ) resin catalysed by $1.5 \%$ by weight MEKP. Fibre content is $55-60 \%$ by weight.

Seven panels were produced over a two month period. The first 8 plies of six of the panels were impregnated the same day. Three of these panels were protected with polyamide 66 peel plies (referred to as $\mathrm{P}$ ), the other three were left exposed to the air (referred to as $\mathrm{N}$ ). All were stored in a temperature and humidity controlled environment $\left(20^{\circ} \mathrm{C} 50 \% \mathrm{RH}\right)$. After one day, one week and 6 weeks a second series of 8 plies was laminated onto the first 8 plies, after removing the peel plies when present. An 8 micron thick polypropylene starter film was included at mid-thickness. No additional surface preparation was performed before overlamination. The seventh panel was laminated continuously from the same resin and fibres, in order to provide a reference and to determine how the aging of the composite with time affected fracture behaviour.

Table 1. Panel thicknesses

\begin{tabular}{|c|c|c|}
\hline $\begin{array}{c}\text { Time between first substrate } \\
\text { fabrication and overlamination }\end{array}$ & Surface preparation & $\begin{array}{c}\text { Mean thickness, mm } \\
\text { (standard deviation) }\end{array}$ \\
\hline 0 & Continuous & $7.7(0.1)$ \\
\hline 1 day & No peel ply & $7.8(0.1)$ \\
& Peel ply & $7.7(0.1)$ \\
\hline 1 week & No peel ply & $8.1(0.2)$ \\
& Peel ply & $7.9(0.1)$ \\
\hline 6 weeks & No peel ply & $8.3(0.1)$ \\
& Peel ply & $8.2(0.1)$ \\
\hline
\end{tabular}

\section{Tests performed}

First, measurements were made using Dynamic Mechanical Analysis (DMA, TA Instruments 2980 ) in order to follow the cure of the composite matrix with time. Samples $10 \mathrm{~mm}$ wide, 60 mm long and 4mm thick, (half the DCB specimens described below, taken from the starter film end of untested specimens), were loaded in three point flexure at $1 \mathrm{~Hz}$. Temperature was increased at $10^{\circ} \mathrm{C}$ per minute.

Mechanical tests were then performed on standard short beam shear (ILSS ASTM 2344), three point flexure (ASTM 790) and mode I double cantilever beam (DCB) specimens (ISO 15024). ILSS specimens were $10 \mathrm{~mm}$ wide with $40 \mathrm{~mm}$ between supports $(\mathrm{l} / \mathrm{h}=5)$. Three point flexure specimens were $15 \mathrm{~mm}$ wide and $\mathrm{l} / \mathrm{h}$ was equal to 16 . DCB test specimens were 35 or $50 \mathrm{~mm}$ wide with $60 \mathrm{~mm}$ long 8 microns thick polypropylene starter films at midthickness, Figure 1. 
Figure 1. DCB specimen under load.

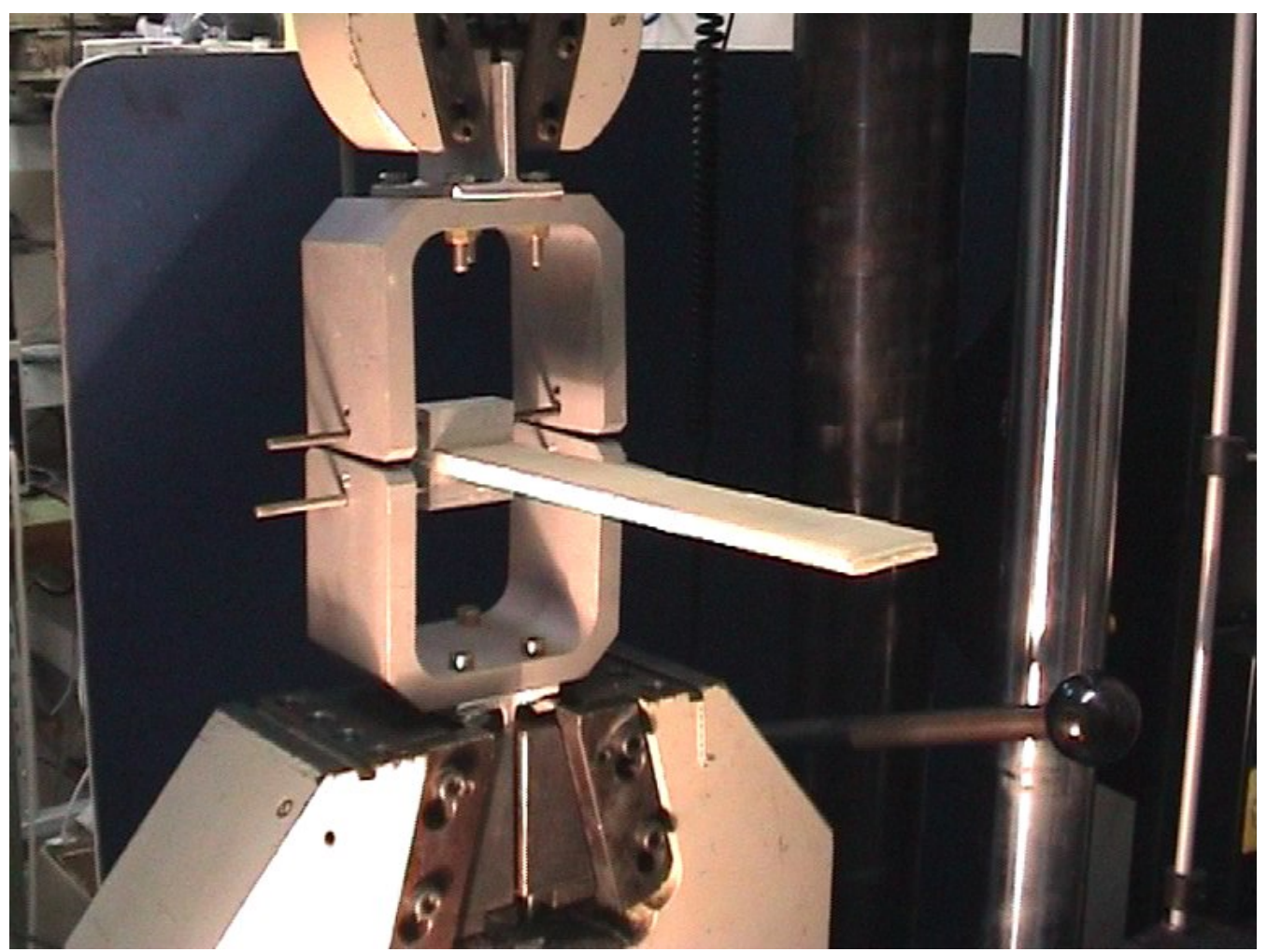

Load P, opening displacement $d$ and crack length a were measured during tests. Values of $G_{\text {Ic }}$ were then determined using the expression:

$$
\mathrm{G}_{\mathrm{Ic}}=\mathrm{nPd} / 2 \mathrm{Ba}
$$

where $n$ is an empirical parameter, the slope of a compliance (d/P) versus crack length plot, and $\mathrm{B}$ is the specimen width [9]. Each specimen provides an initiation value and several propagation values as the crack advances. Due to the small number of specimens only the propagation values were used here, defined as all values measured beyond the first $20 \mathrm{~mm}$ of propagation. These values are generally not retained in standard test methods for specimens with unidirectional fibres as bridging effects can result in propagation values which depend on specimen thickness [10]. For woven reinforcements such as those employed here the values can be used as no fibre bridging was noted.

After testing fracture surfaces were coated with Au-Pd alloy and examined in a scanning electron microscope (Jeol JSM 6460L).

\section{Test procedures}

A first series of tests was performed on specimens from the continuously laminated panel, in order to determine the influence of time between fabrication and testing, Table 2. This parameter may affect the results obtained, although all the subsequent tests performed to study surface preparations were carried out at the same time so it will not affect the comparison between the two surface preparations. Nevertheless it is well known that the cure of polyester resins is not instantaneous so this parameter is of interest for practical applications, and in particular it is important to know how long it takes for stable properties to 
be attained. The time between fabrication and launch of small boats may be as short as 3 weeks.

Table 2. First series of tests. Influence of time after fabrication.

\begin{tabular}{|c|c|c|}
\hline $\begin{array}{c}\text { Time between first substrate } \\
\text { fabrication and overlamination }\end{array}$ & Surface preparation & $\begin{array}{c}\text { Period between } \\
\text { overlamination and } \\
\text { testing (days) }\end{array}$ \\
\hline 0 & Continuous & $3,7,15,21,28,56$ \\
\hline
\end{tabular}

The main test series was then performed on specimens from all seven panels. The conditions for these tests were the following (Table 3).

Table 3. Second series of tests. Direct comparison, ILSS and DCB tests.

\begin{tabular}{|c|c|c|}
\hline $\begin{array}{c}\text { Time between first } \\
\text { substrate fabrication } \\
\text { and overlamination }\end{array}$ & Surface preparation & $\begin{array}{c}\text { Period between overlamination } \\
\text { and testing (days) }\end{array}$ \\
\hline 0 & Continuous & 56 \\
\hline 1 day & No peel ply & 56 \\
& Peel ply & 56 \\
\hline 1 week & No peel ply & 50 \\
& Peel ply & 50 \\
\hline 6 weeks & No peel ply & 14 \\
& Peel ply & 14 \\
\hline
\end{tabular}

\section{Results}

\section{- Influence of time after fabrication, continuous lamination}

Figure 2 shows typical DMA results for continuously laminated specimen 3 and 60 days after lamination. 
Figure 2. Typical DMA results, 3 and 60 days after fabrication.

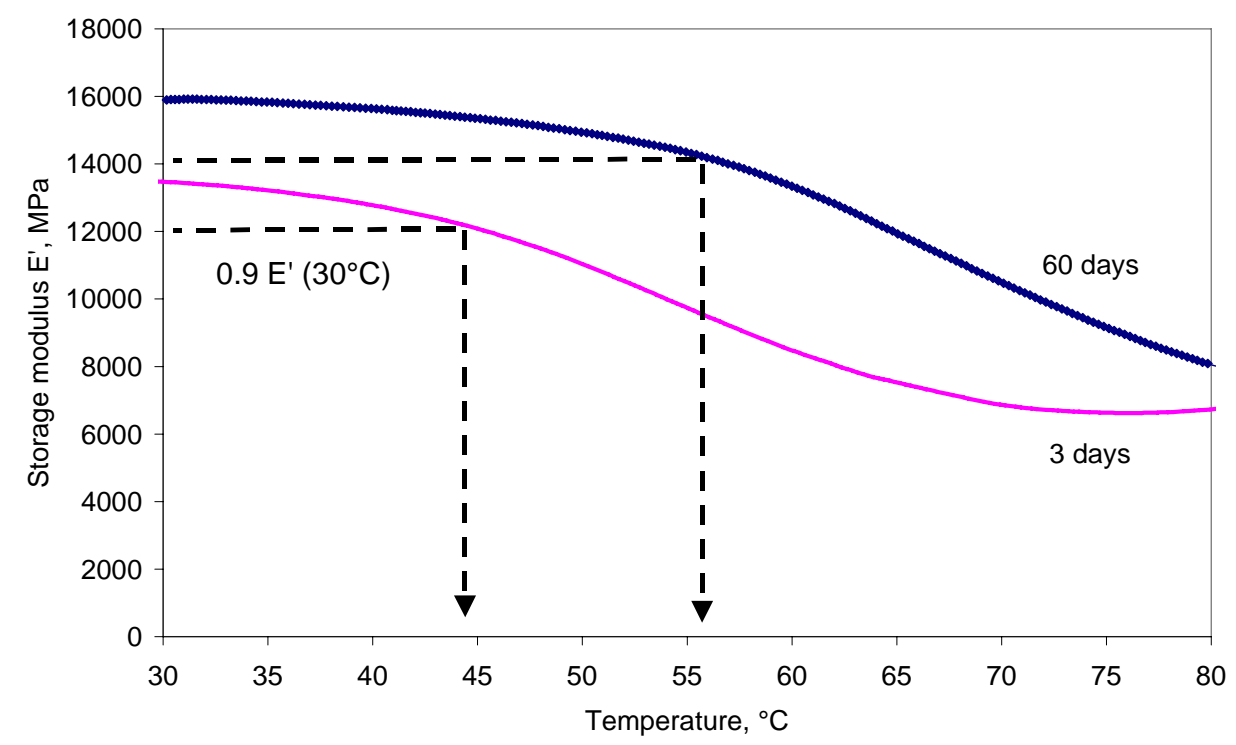

The storage modulus drops with temperature although the absolute values of modulus should be treated with caution, as these are very sensitive to thickness variations. Standard test methods (e.g. ASTM E1640) suggest a definition for the determination of glass transition temperatures from such plots as "the extrapolated onset to the sigmoidal change in the storage modulus". It is difficult to apply this criterion due to the non-linear behaviour before the transition. An arbitrary definition of a $10 \%$ drop in storage modulus compared to the $30^{\circ} \mathrm{C}$ value was therefore employed, Figure 2, in order to compare results for different times after fabrication. Results are shown in Figure 3, together with a value for a post-cured sample. There is some scatter but the results suggest that after about 20 days the modulus values are reasonably stable.

Figure 3. Temperature corresponding to $10 \%$ drop in storage modulus as a function of time after lamination, compared to value for sample post-cured at $50^{\circ} \mathrm{C}$ for 16 hours (dashed line).

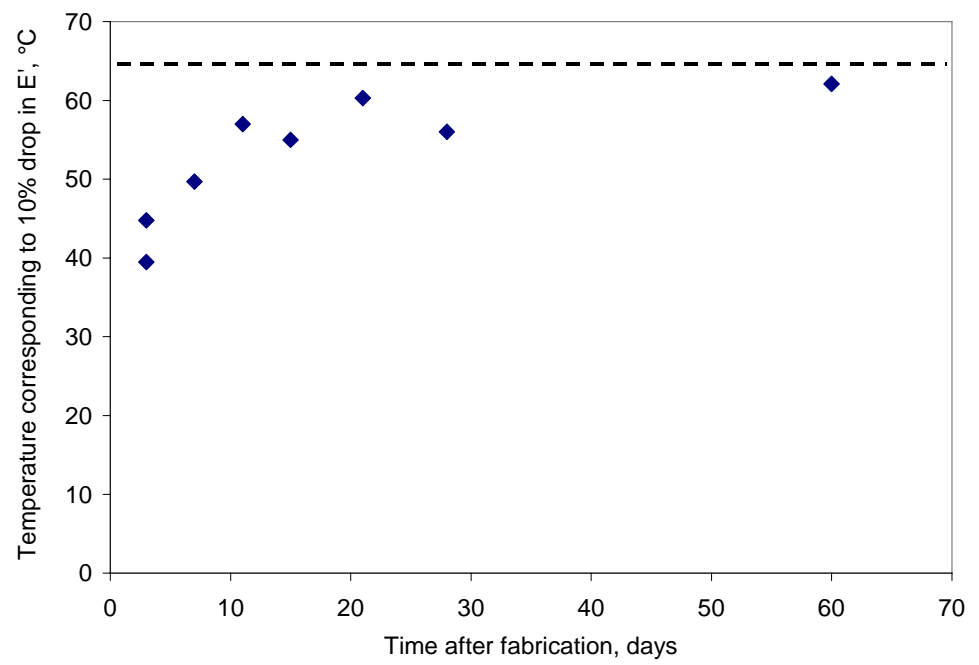


Results from ILSS and DCB tests to examine how failure properties evolved with time after fabrication are shown below. Figure 4 shows the ILSS values, and there is no significant evolution after the first week after fabrication.

Figure 4. ILSS tests, influence of time after fabrication, mean values and standard deviation error bars.

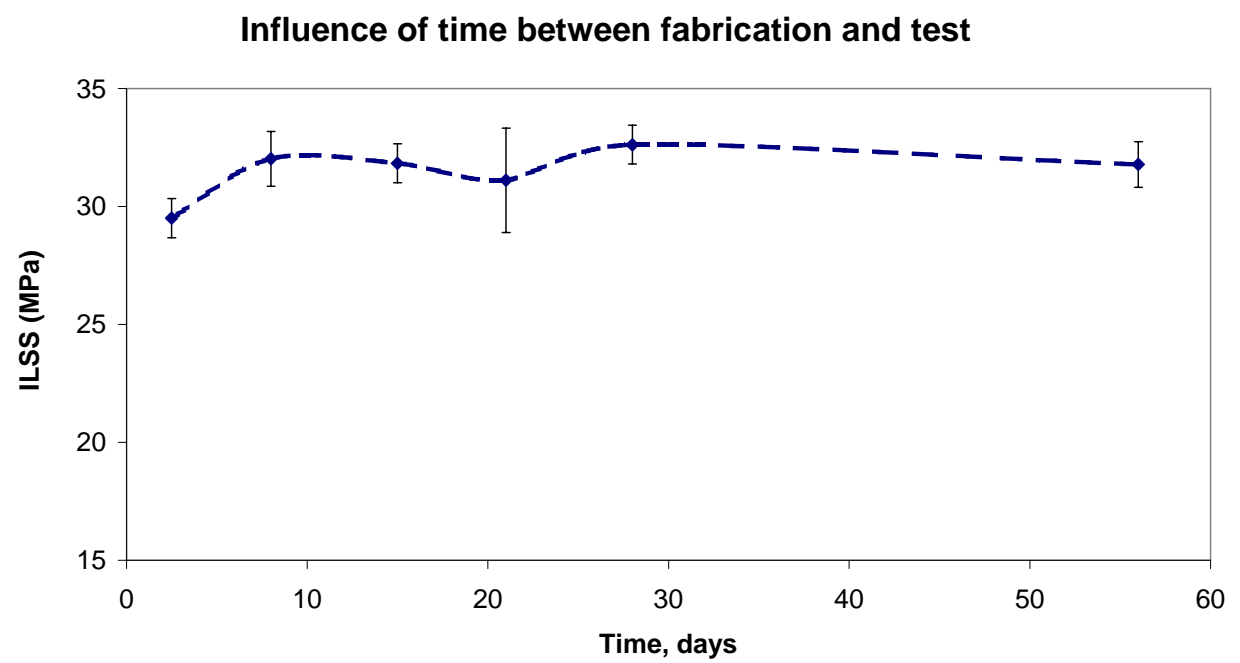

Two DCB specimens were tested at each time and typically six propagation values of $\mathrm{G}_{\text {Ic }}$ were determined for each specimen. The mean and standard deviations are shown below in Figure 5 and there does not appear to be a significant evolution in fracture resistance. This again suggests that the material is quite stable once the first week after fabrication has passed.

Figure 5. Mode I DCB test results, propagation values, influence of time after fabrication, continuously laminated specimens (C), mean values and standard deviation error bars.

Evolution of Glc propagation values with time

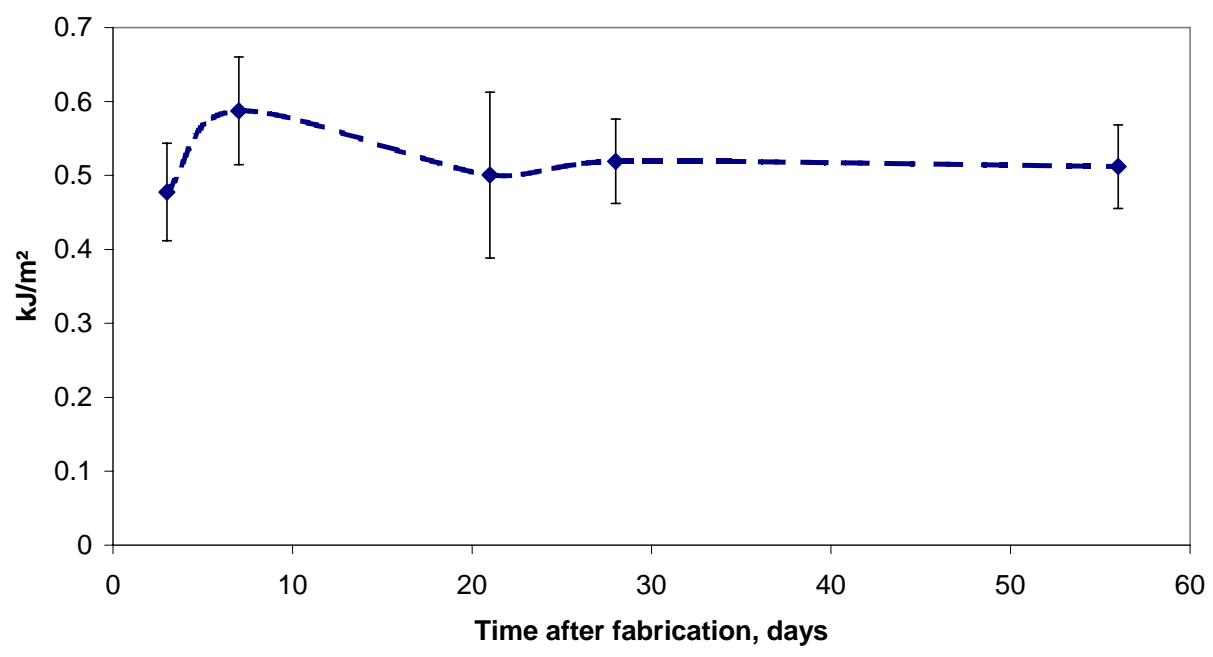




\section{- Influence of surface preparation}

The influence of surface preparation was then examined. Figure 6 shows the results from the short beam shear tests, on at least 4 specimens for each condition.

Figure 6. Short beam shear test results, mean values (standard deviation error bars)

C: Continuous fabrication (test time after fabrication in brackets), P: Peel ply, N: No peel ply ( delay between fabrication of first and second halves in brackets), tests on $P$ and $N$ specimens performed 8 weeks after fabrication started.

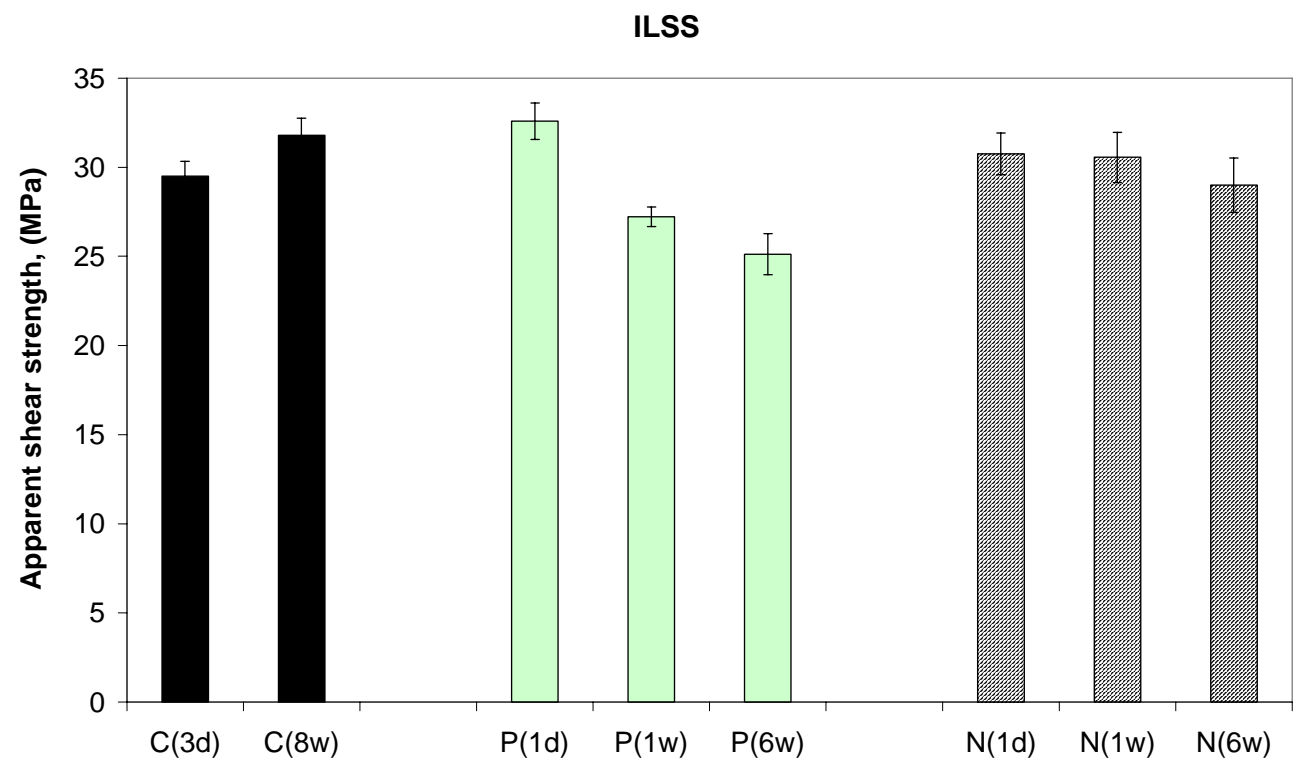

The differences between the highest and lowest of the mean values are quite small, the range is only from 25 to $33 \mathrm{MPa}$ for all the test results. Nevertheless, there do appear to be differences which correspond to the different fabrication conditions, notably lower values for the overlamination onto a surface protected by a peel ply when the delay is one week or more, compared to an unprotected surface, and higher values for overlaminations after shorter delays, but the variations are quite small.

Flexural tests were also performed, again on four specimens for each condition, as these are often employed to characterise marine laminates. Flexural properties are specified in the hull scantling requirements specified in the new draft ISO documents for pleasure boats [11]. These tests showed no significant influence of fabrication conditions on flexural strength, Figure 7, as might be expected; the strength is dominated by the outer layers of the specimen. 
Figure 7. Mean flexural strengths (standard deviations error bars).

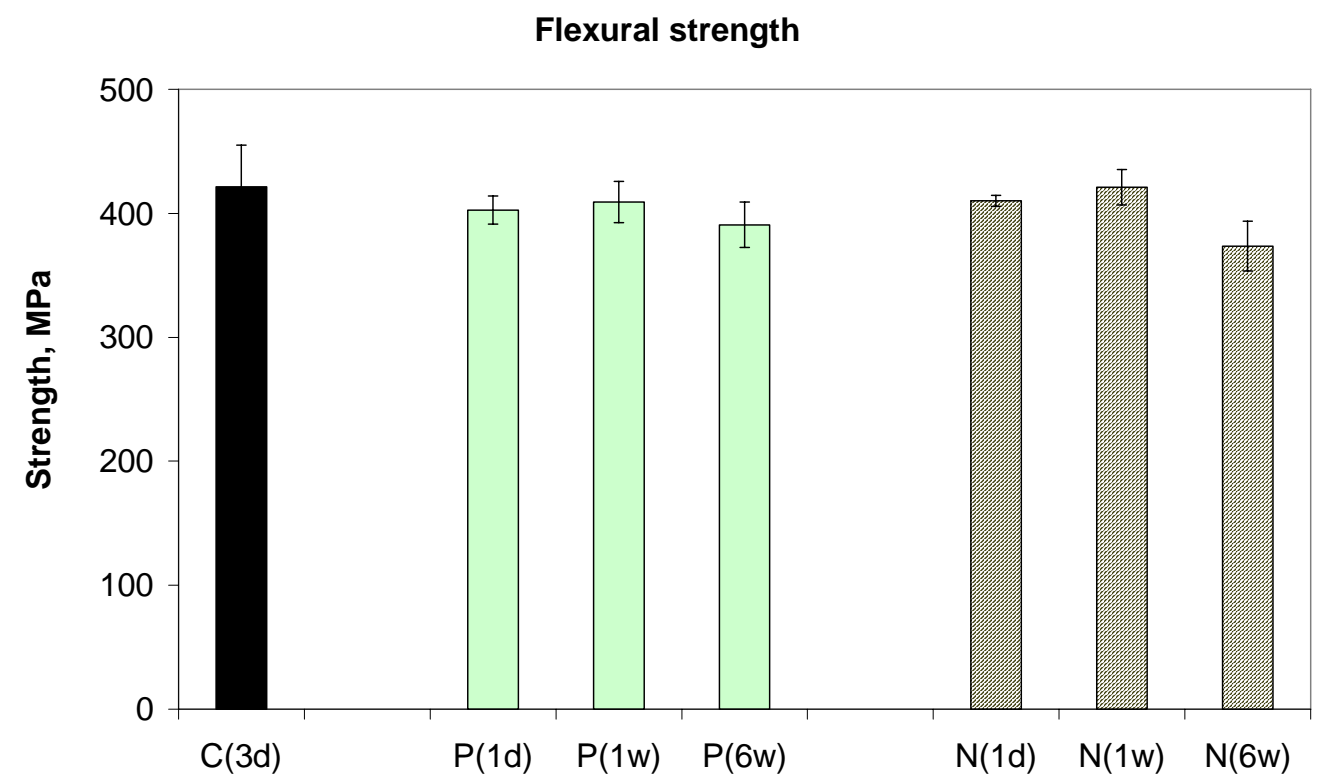

Mode I DCB tests were then performed on 2 or 3 specimens for each condition. This is a small number of specimens, (though each specimen provides several propagation values), as this was a preliminary study to establish whether the fracture mechanics tests could provide useful information rather than a full characterisation campaign.

Figure 8 shows examples of load-displacement plots for the different manufacturing conditions.

Figure 8. Examples of DCB load-displacement plots

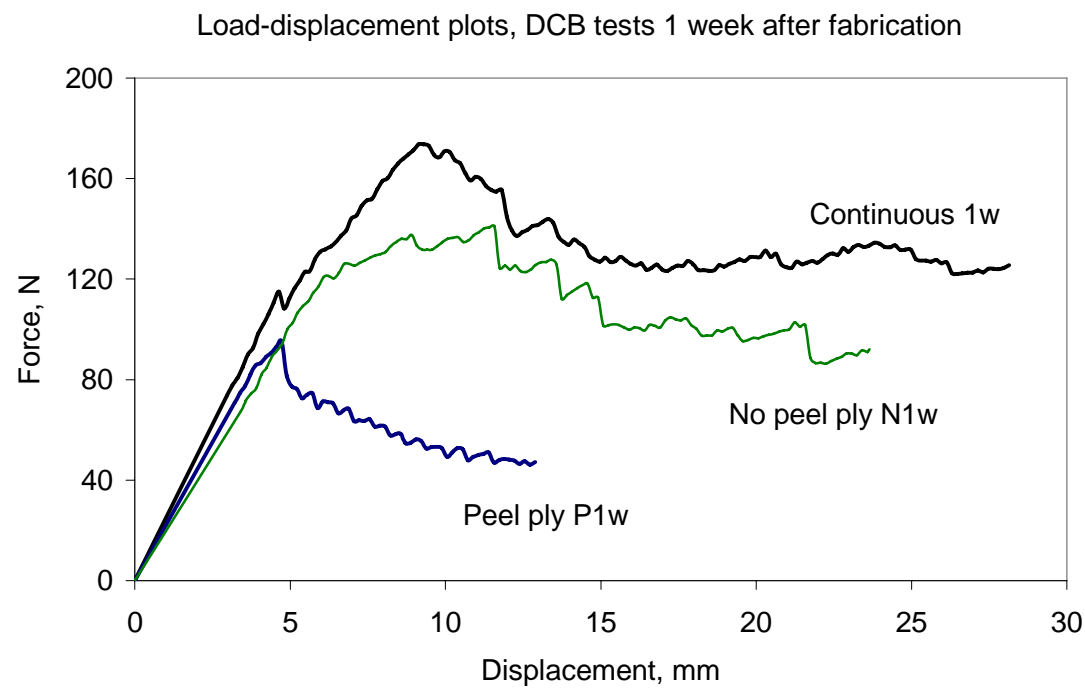


From these plots compliance calibrations were performed for each specimen and R-curves $\left(G_{c}\right.$ versus crack length) were determined, Figure 9. Values at initiation are similar for all specimens, between 100 and $200 \mathrm{~J} / \mathrm{m}^{2}$, but there are very significant differences for propagation values.

Figure 9. Examples of mode I R-curves for different fabrication conditions

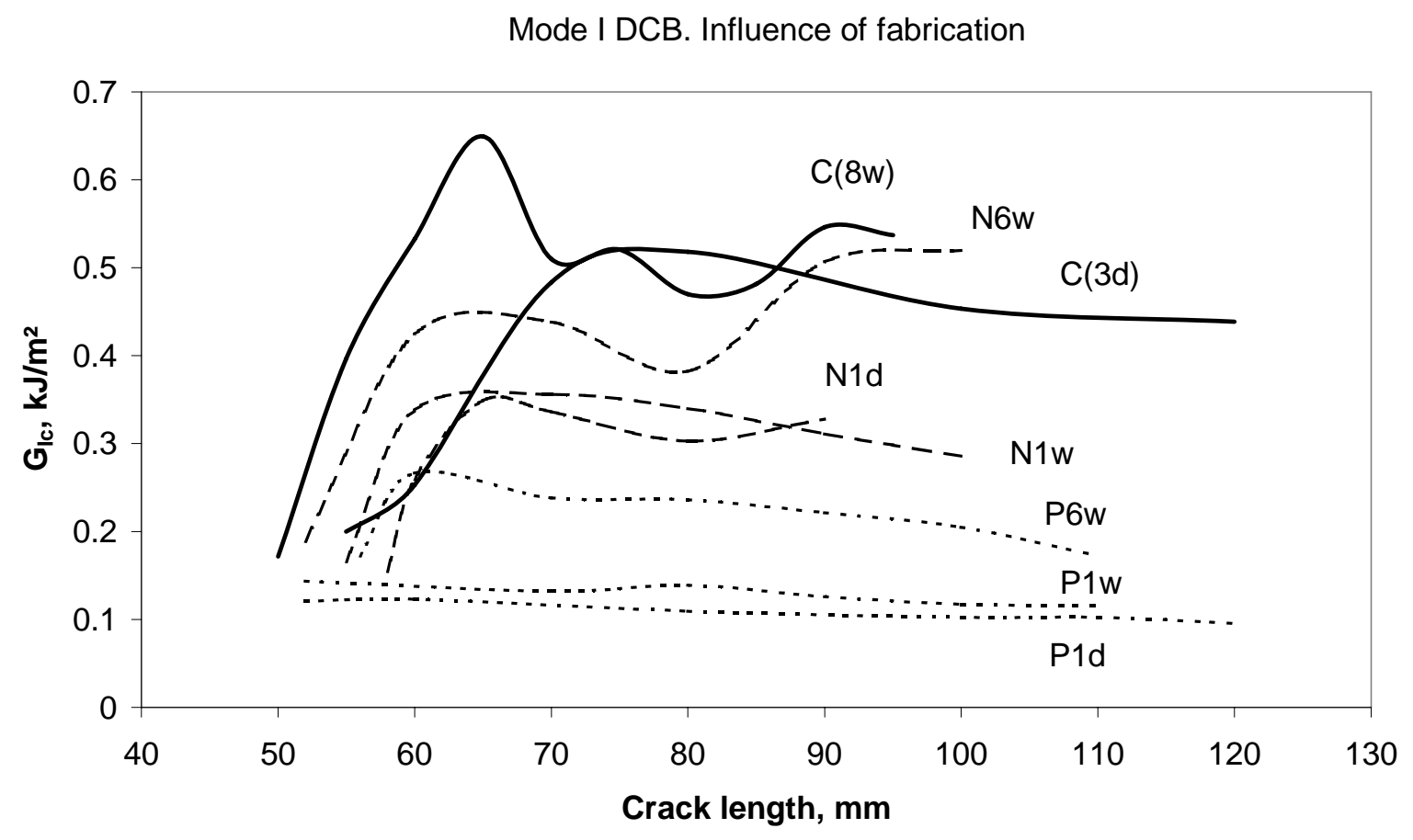


Figure 10 summarises the results.

Figure 10. Summary of mean mode I propagation values (error bars show standard deviations).

\section{DCB Propagation values}

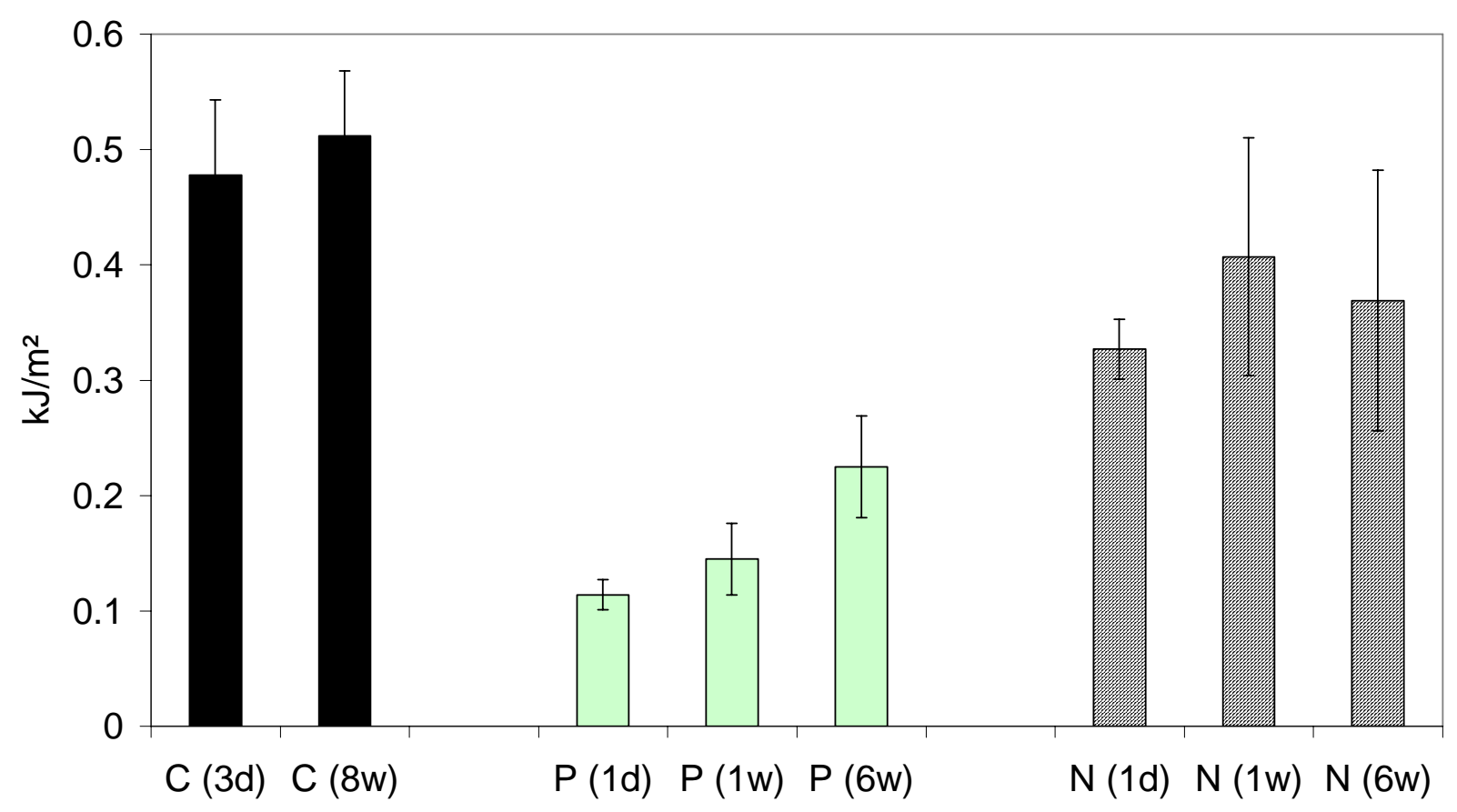

The crack resistance of the central interface in a panel produced by continuous lamination is higher than all those produced in two lamination steps, even when the delay between the steps is only one day. It is also much easier to propagate a crack at the mid-plane interface when a peel ply is used than when the surface has not been protected. This rather surprising result will be discussed further below.

These results suggest that neither of the tests currently used to characterise marine laminates is particularly sensitive to the influence of manufacturing conditions on the integrity of the mid-plane interface. If these conditions are to be optimised with respect to damage tolerance and crack propagation the mode I DCB test appears to be a more useful method.

\section{- Microscopic examination}

Figures 11 and 12 show the fracture surfaces of DCB specimens manufactured by continuous lamination and with a peel ply. 
Figure 11. Fracture surface of continuously laminated DCB specimen Crack direction is vertical.
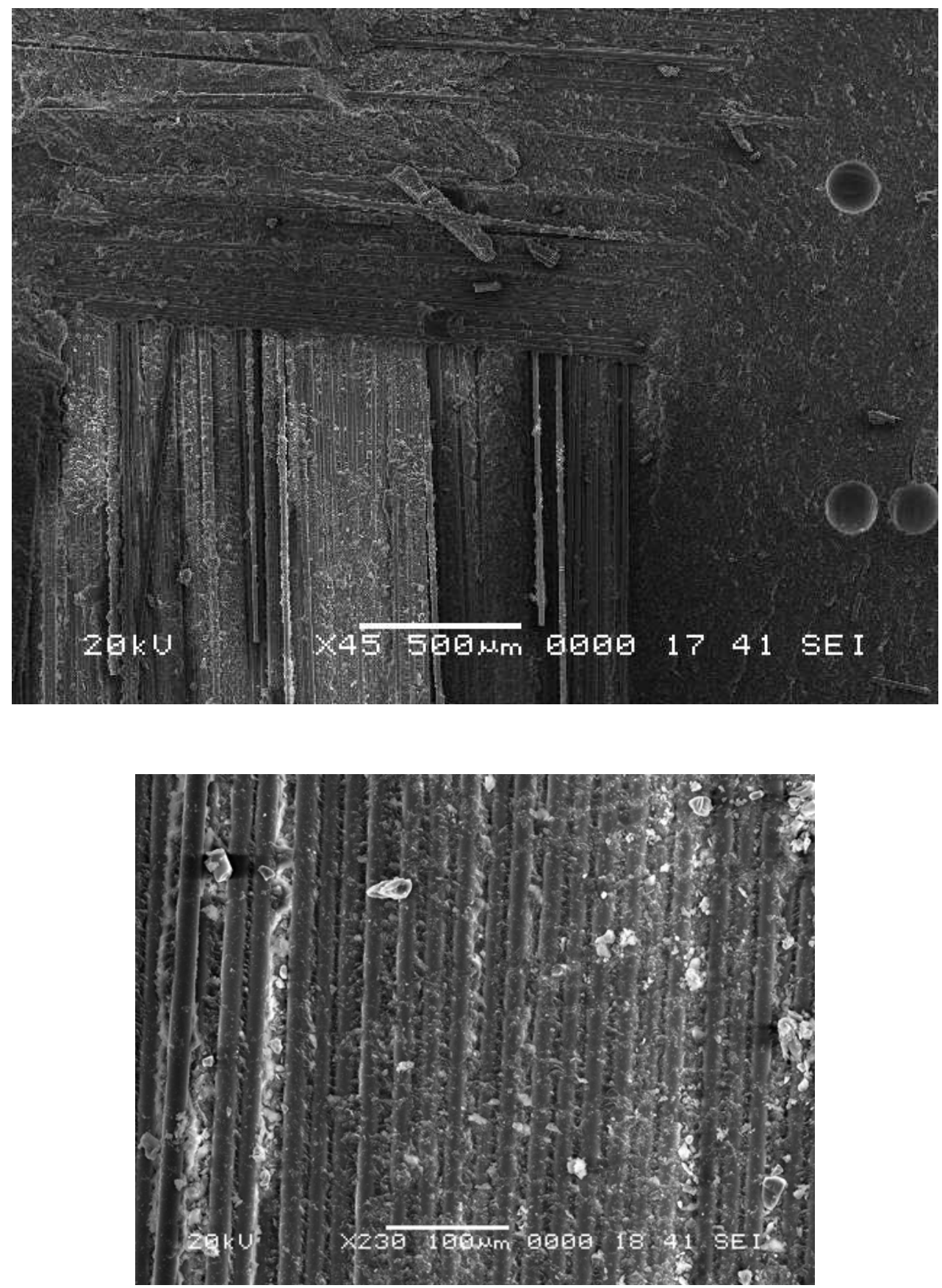
Figure 12. Fracture surface of DCB specimens protected by peel ply. Crack direction is vertical.
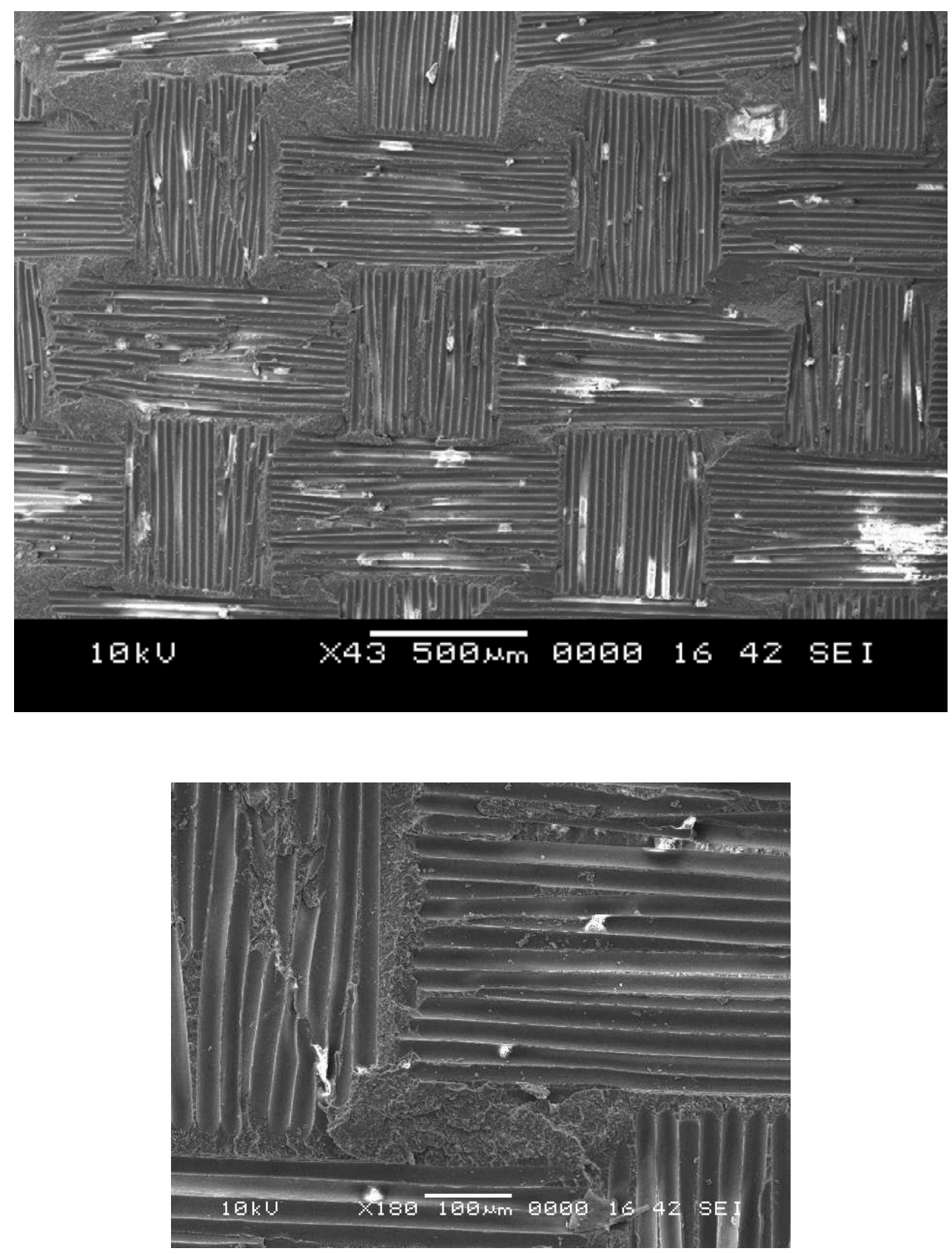

It is clear that overlamination directly after removing the peel ply results in poor adhesion, there are only isolated regions of bonding and this results in very low fracture energies. The imprint of the peel ply is clearly visible, Figure 12. This may be due to surface contamination by the peel ply. Further surface analyses are needed. One solution would be to use further surface preparation such as grinding to create a new surface before overlamination and such preparations are used in some boatyards, but this is certainly not universal practice. 


\section{Further considerations}

The initial aim of these tests was to establish whether there were advantages to using fracture mechanics tests rather than the conventional ILSS or three point flexure to reveal effects related to changes in manufacturing conditions. The results shown above certainly suggest that the mode I DCB tests are very sensitive to such changes, at least for the type of glass reinforced polyester system cured at room temperature commonly used in marine structures. In interpreting the results several additional factors need to be considered.

One consideration is that although all the specimens contain the same number of reinforcement layers the mid-plane lamination region thickness is not the same for the three conditions (continuous, overlaminated unprotected and with a peel ply). Thickness measurements and examination under the microscope reveal that the continuously laminated specimens are thinner than the overlaminated specimens as mentioned earlier (Table 1), particularly after a delay of 6 weeks. This is due to resin rich regions being produced at the mid-plane when the lamination is restarted after a delay. This difference is a consequence of the fabrication process, and hence a real effect which will be seen in practice. The thicknesses of overlaminated specimens are similar for each delay period so these comparisons are valid but there may be a bias in the comparisons between different delay periods.

The thickness of the resin-rich region is one parameter which will influence interlaminar crack resistance. The type of reinforcement will affect this thickness and may also determine fracture surface roughness. The mechanical, physical and chemical properties of the surfaces before overlamination may all be important and all can change with time. For example, the presence of oxygen tends to inhibit the cross-linking reaction by partially de-activating the free radicals produced by peroxide decomposition. The cure of surfaces in contact with air (without peel ply) may therefore be inhibited, resulting in a tacky surface which is more receptive to overlamination [3]. However, other factors may also contribute, namely the evaporation of styrene from the surface, resulting in a change in local stoichiometry and the appearance of an interphase [12] which may also affect adhesion. A lower temperature at the surface may also result in a slower reaction. The presence of a peel ply may result in a more complete cross-linking reaction but the peel ply may not be a complete barrier to oxygen and styrene. This surface chemistry is complex and requires more detailed study if surface preparations are to be optimised.

\section{Conclusions}

The conventional interlaminar shear strength test frequently used for quality control is shown to be relatively insensitive to significant differences in manufacturing conditions. The mode I fracture mechanics test appears more sensitive to these conditions and may offer potential for the optimisation of fabrication parameters. Significant differences were noted between the mode I fracture resistance of specimens fabricated under different conditions with very low fracture resistance of interfaces protected by peel plies. Further tests are being performed to investigate these differences, but the results indicate the need to remove the resin layer which has been in contact with the peel ply before overlaminating. 


\section{References}

[1] Smith CS, Design of Marine Structures in Composite Materials, Elsevier, London, 1990.

[2] Mouritz AP, Gellert E, Burchill P, Challis K, Review of advanced materials for naval ships and submarines, Comp. Structures, 53, 2001, 21-41.

[3] Skrifvars M, Berglund L, Ericson M, Microscopy of the morphology in low styrene emission glass fiber/unsaturated polyester laminates, J. Appl. Polymer Sci., 71, 1999, 15551562.

[4] Davis M, Bond D, Principles and practices of adhesive bonded structural joints and repairs, Int. Jnl Adhesion \& Adhesives, 19, 1999, 91-105.

[5] Hart-Smith LJ, A peel type durability test coupon to assess interfaces in bonded, cobonded and co-cured composite structures, Int. Jnl. Adhesion \& Adhesives, 19, 1999, 181191.

[6] Armstrong KB, Effect of adsorbed water in CFRP composites on adhesive bonding, Int. Jnl Adhesion \& Adhesives, 16, 1996, 21-28.

[7] Chin JW, Wightman JP, Surface characterization and adhesive bonding of toughened bismaleimide composites, Composites Part A, 27A, 1996, 419-428.

[8] Baley C, Davies P, Grohens Y, Dolto G, Application of interlaminar tests to marine composites: a literature review, Applied Comp. Mats, 11, 2004, 99-126.

[9] Berry JP, Determination of fracture surface energies by the cleavage technique, Jnl Applied Physics, 34, 1963, 62.

[10] Moore DR, Pavan A, Williams JG, Fracture mechanics testing methods for polymers, adhesives and composites, ESIS publication 28, Elsevier, 2001.

[11] ISO/DIS 12215, Part 5 Design pressures for monohulls, design streses, scantlings determination, 2003.

[12] Shah CB, Rockett TJ, A diffusional interphase in layered polyesters, J. App Polymer Sci, 59, 1996, 263-267. 